\title{
Revelation of Laozi's Thought to Secretarial Work
}

\author{
Wanqing Liu ${ }^{1, *}$ \\ ${ }^{1}$ School of China Metrology University of Humanities \& Foreign Languages, Hangzhou, Zhejiang 310018, China \\ *Corresponding author. Email: 675055469@qq.com
}

\begin{abstract}
As the founder of the traditional Chinese Taoist school, Laozi's thoughts are rich in profound truths. Laozi's thoughts are mainly gathered in the book Tao Te Ching, which contains the ideas of "Tao", "Wu Wei" and "Dialectics". In this paper, we analyze the content of Laozi's Tao Te Ching, and focus on some problems in modern secretarial work. From three aspects of learning work, dealing with the world and cultivating body and mind, the inspiration of Laozi's thought to secretarial work is explored.
\end{abstract}

Keywords: Laozi's thought, Tao Te Ching, secretarial work, inspiration

\section{INTRODUCTION}

With the vigorous development of China's economy and politics, the secretarial industry has also grown. Both administrative departments and enterprises and institutions are in urgent need of a large number of secretarial professionals, but at the same time of the rapid development of the secretarial industry, the requirements for secretarial work in all walks of life have been increasing, and the problems in secretarial work are also being exposed. And in this paper, by analyzing the content of Laozi's Tao Te Ching, we find many ideas that have significance for secretarial work. Secretaries have to learn many truths in their work, if they do not learn to work carefully and have no initiative, then how can they serve the leaders better; in dealing with people, without a humble attitude, how can they grasp the balance between leaders and colleagues appropriately; in cultivating body and mind, they cannot clean themselves and repay their grievances with virtue, and how can they improve their overall quality. In short, from Laozi's ideas can be drawn out many valuable inspiration for secretarial work, these ideas can promote secretarial work more professional, professional and standardized.

\section{LAOZI'S THOUGHT AND THE TAO TE CHING}

\subsection{The Idea of "Tao"}

Many studies have shown that the idea of "Tao" was first proposed by Laozi, and it is the core of Laozi's thought. "The Tao is not simply a path, but includes abstract meanings such as laws and principles. For example, in the first chapter of the Tao Te Ching, it is said, "Tao, can be the way, but not the way."[2] Here, "Tao" is not the general Tao, but the law that all things change and develop according to, and all changes come back to the same way in the end. The philosophical idea of "Tao" in the Taoist school, seemingly nebulous and inscrutable, is actually equivalent to a methodology, which not only had an important influence on the thinking of Confucianism, Mohism and Buddhism in the Spring and Autumn Period, but also is one of the sources of modern excellent thinking.

\subsection{The Idea of "Wu Wei"}

The Tao Te Ching also mentions "rule by doing nothing" many times, where "doing nothing"[2] is not inaction, but following the natural laws of development and not acting presumptuously. "The reason why a sage can rule without doing anything is that he sees the natural law of development and consciously follows it, so as to achieve the harmony between man and nature and realize the realm of "unity of heaven and man"[3]. The idea of "Wu Wei" is usually applied in modern society as a management method in enterprises and governments, and it has a high significance for building a harmonious relationship between human beings and society.

\subsection{The Idea of "Dialectic"}

Dialectics in Laozi's thought is the earliest dialectical thought that can be traced in China. Regarding dialectics, the Tao Te Ching mainly embodies three kinds of discursive ideas. One, Laozi believes that the two sides of contradiction exist in opposition to each other and that things are constantly changing and developing. For example, beauty and ugliness, good and evil, high and low, blessing and curse, they are not absolute, but complementary. People should pay attention to the development of things, get inspiration from them, and see the two sides of things. Secondly, the idea of discernment is also reflected in the relationship of discerning unity between two sides of contradiction. The Tao Te Ching often mentions the relationship between "something" and "nothing", where "something" and "nothing" are unified in the same Like a house, the outside walls and the hollow space inside are combined together to make it a house for 
people to live in and play their role. Third, the development of things is not sudden, but a process of change from "gradual" to "significant". A large tree grows from a seedling, and a nine-story high platform is built from clay. The development of anything is not overnight, and it is necessary to focus on the process of accumulation, to learn and to pay attention to the details, since the details determine success or failure sometimes. In conclusion, Laozi's discerning thoughts not only had a positive effect on the society at that time, but also have many inspirations for today's world.

\section{PROBLEMS in SECRETARIAL WORK}

With the continuous development of social politics, economy and culture, the secretarial industry of our country has also made great progress, but at the same time, the secretarial work has also exposed the following problems.

\subsection{The Secretarial Work Is Heavy, The Innovation Consciousness Weakens}

If you want to generalize the nature of secretarial work in one sentence, it is to serve the leadership. Thus, the object of secretarial work is unitary, that is, to serve their respective superior leaders. The term "private secretary" shows this kind of professional relationship incisively and vividly. The secretary should not only pay attention to the work of the leader but also pay attention to the life of the leader, which increases the workload of the secretary invisibly. As the saying goes, "Today is the day." But in addition to planning the day's schedule, the secretary also arranged the materials needed for the next day. So the secretary's work is very heavy, it is not as bright as people think. And because the secretary listens to his own leadership for a long time, the single object of service is likely to make the secretary afraid of the authority of the leadership, develop the character of "submissive ", dare not express his own views, thus weakening his sense of innovation.

\subsection{The Attitude and Manner of Communication Need to be Improved}

Secretary in enterprises and institutions usually play a connecting role, coordination of all parties, many people also regard the secretary as the embodiment of leadership, the facade of the unit. Therefore, it is very important for secretaries to have the correct attitude and manner of dealing with people. In today's information-rich society, if a secretary does not find his own position and conveys the command of the leader in an arrogant and rigid manner, then through the fermentation of the network, he may damage not only his own image. There is also the image of the unit. Since the secretary plays a connecting role, his communication object is mainly the superior leader and the subordinate staff, but in the conduct of people, some secretaries often play the role of "double-faced ", respectful to the leader, but very arrogant to the subordinates, even some secretaries regard this as a normal. In fact, if these secretaries do not change the attitude and manner of doing things, the ultimate harm is not only themselves and companies, but also society.

\subsection{Low Physical and Mental Literacy, Confounding The Boundaries of Fame and Fortune}

From its own point of view, some secretaries themselves low literacy, can not meet the needs of the work. Because of the particularity of his position, the secretary has a close relationship with the leader, which makes some secretaries confuse themselves with the personal relationship and the working relationship of the leader, the boundary of the work responsibility is not clear, and they often regard themselves as the "two leaders" of the company [4]. Especially in this impetuous society in modern times, some secretaries face the temptation of some fame or money, rely on their own right to assist the leadership decision-making to mislead the leadership decisionmaking, even ultra vires, and finally embark on the road of corruption and crime. It can be seen that the low personal accomplishment of secretaries in secretarial industry is also a very serious problem in modern society.

\section{REVELATION OF LAOZI'S THOUGHT TO SECRETARIAL WORK}

In this modern network technology developed society, no matter how small a mistake can be infinitely magnified, secretarial work exposed problems are no exception. In Laozi's classic moral classics, we can find that the ideas of "Tao "," inaction" and "dialectics" will enlighten the secretary in the imperfect places of study, work, conduct and personal quality. Through the study of these ideas, we can effectively improve the problems exposed in the secretarial work.

\subsection{Work Philosophy of "Words Have a Clan"}

"Words have a clan, things have a king (Tao Te Ching, Chapter 70).[2] According to Laozi, one should have one's own opinion in speaking and doing things, learn to see through confusion, grasp the essence, not blindly follow the crowd, and learn to enhance individual consciousness. The passivity of secretarial work makes secretaries largely lack independence and can only give orders with reference to the wishes of leaders. After a long period of work many secretaries gradually lost their individual consciousness in their work, even if they have their own ideas for some programs, they are forced to fear the leadership and dare 
not put them forward. Most secretaries in the traditional sense of the work mode is "obedient", do not dare to take the initiative. But if the secretary has a better solution to the problem, why can not propose it? Sometimes a timely and reasonable proposal may improve the efficiency of the whole team. As a secretary in the new era, should not only listen to the leadership, but also learn to express their own views at the right time and occasion, and constantly improve the secretary's own individual awareness and sense of innovation.

\subsection{The Attitude of "No Enterprise, No Cross- line"}

The secretary, as the pivot of the office uploading and sending down, is dealing with others all the time, and he is faced with a large and complicated network of people. And how to deal with this relationship, Lao Tzu in the "Tao Te Ching" twenty-four chapters said a piece of wisdom for dealing with people. "[2] The enterprise is not established. Those who straddle do not work. Those who see themselves are unknown. The one who is self is not manifest. He who self-fells has no success." According to Lao Tzu, those who stand on tiptoe cannot stand steadily; those who take big steps do not go far; those who think they have insight are actually not wise; those who think they are right do not highlight their intelligence instead; those who work brutally on their own do not achieve much; and those who praise themselves do not gain the corresponding prestige. There is nothing wrong with having a positive and aggressive heart, but if you are therefore arrogant and self-righteous, it will often backfire and pay a greater price, such as Xiang Yu who killed himself on the Wu River. When he let Liu Bang go at the Hongmen Banquet, he showed his headstrong character and hinted at his fate. If he had chosen to return to Jiangdong at the Wujiang River, he might have been able to make a comeback and change the situation. The river of history does not flow backwards, we should learn from history and learn the wisdom of the ancients to deal with things modestly. As a secretary in the new era, we should do things in a low profile and maintain a modest attitude when dealing with people.

\section{3. "Life Cultivation of "the Way to Simplicity}

The secretary's work ability is related to the efficiency of his unit, and the secretary's personal character cultivation is the key to his work, so to a certain extent, the secretary's physical and mental qualities are extremely important to a unit or enterprise. Just as a person's physical health and spiritual health are equally important, the secretary should improve his or her own quality at the same time as his or her professional quality is improved. Laozi's "Tao Te Ching" mentions the idea of "Wu Wei" many times. Putting the idea of "inaction" in the "dialectic" to think, it reminds people not to be too obsessed with external things, but to see the intrinsic value of people. Secretary industry because of the special nature of its position, surrounded by a variety of temptations, some secretaries and the leadership of the relationship is closer, they flatter, in order to promote, and some secretaries take advantage of its position of foxes and tigers, submissive. So this requires the secretary in the work must be careful, clean, and happy to be unsung heroes, these qualities help to eliminate the public misunderstanding of the secretarial profession. After experiencing all kinds of things in the world, Laozi felt that no matter where he was, he should keep his inner peace and indifference and not be tempted by external things. In order to pursue fame and fortune, the world has given up the freedom and happiness in life, and has been busy all his life. Laozi, on the other hand, followed the principle of "The Way to Simplicity", looking down on fame, fortune and wealth, not to be in the same stream with the world, and let life be in a quiet, natural state. If the staff engaged in secretarial work learn these excellent method of cultivation, they can improve their personal cultivation, and correctly view the relationship between fame and fortune, so that they can get twice the result with half the effort in the actual work.

\section{CONCLUSION}

In short, China's secretarial profession, while booming with social prosperity, has also exposed many problems such as low innovation consciousness, inappropriate ways of interaction and poor physical and mental quality. At present, the re-mining and promotion of Laozi's philosophical thoughts can not only provide theoretical guidance for the problems existing in secretarial work, but also have important significance for secretaries' personal working attitude, way of dealing with things, and physical and mental cultivation.

\section{REFERENCES}

[1] Zhan Fuman; Ming Ming, Government Secretaries in the New Period, Public Publishing House, Beijing, China,2004, pp. 96-97.(In Chinese)

[2] Chen Gu Ying, Annotation and Evaluation of Lao Zi, China Publishing House, Beijing, China, 1984, pp. 174-203. (In Chinese)

[3] Chen Hui, A Brief Discussion of the Tao Te Ching and Personal Cultivation, Xi'an Social Sciences, 2011(5), pp. 10-12,18. (In Chinese)

[4] Wang Jingxin, On How to Improve the Administrative Quality of Modern Secretaries, Office operation, 2016(18), pp. 92-93. (In Chinese)

[5] Bao Xiangdong, Brief Analysis of the Influence of Secretary Philosophy on Secretariat Affair, Office operations, 2019(15), pp. 83-84.(In Chinese) 
[6] Wu Jian, Modern Secretarial Quality Theory,

Journal of Hunan Business School, 2001(02), pp. 91-

93. (In Chinese)

[7] Li Wei, An Overview of Laozi's Thought,

Literature: Theoretical Edition, 2011(5), pp. 162-163.

(In Chinese) 